\title{
Endoscopic ultrasound guided gastroenterostomy for efferent jeunal loop obstruction in a patient with previous pancreaticoduodenectomy and ascites $\square$
}

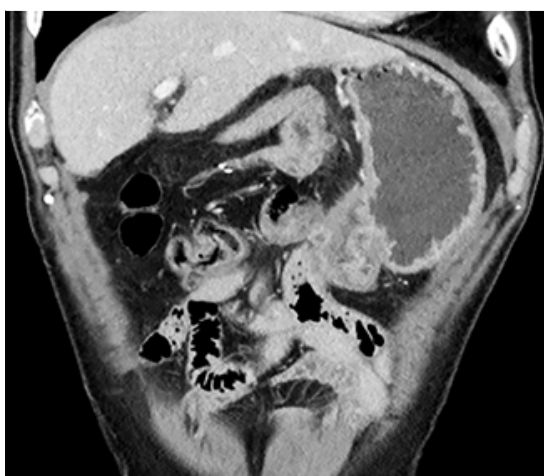

- Fig. 1 Computed tomography scan showing the tumor recurrence at the duodenal-jejunal anastomosis and efferent limb with peritoneal carcinomatosis and small amount of ascites.

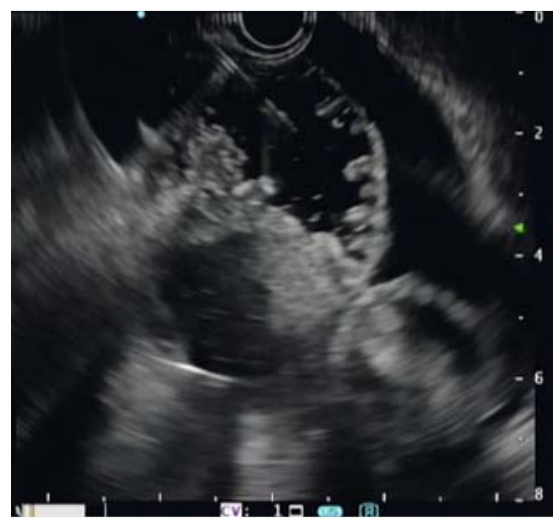

- Fig. 2 Endoscopic ultrasound (EUS) image showing the puncture of the small bowel loop close to the stomach within ascitic fluid with a 19-gauge needle.

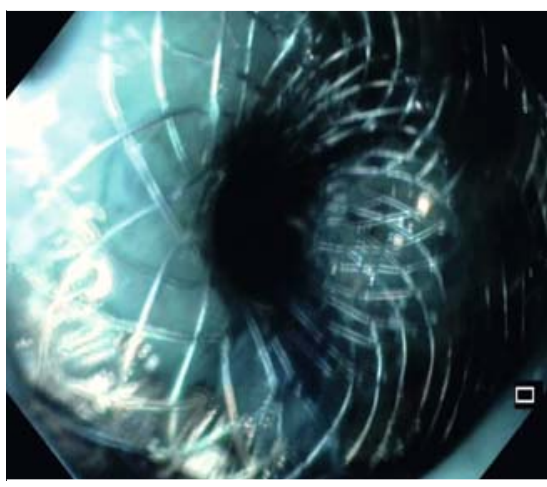

- Fig. 3 Confirmation of correct placement with aspiration of blue fluid across the stent into the stomach.
A 68-year-old man, who underwent pylorus-preserving pancreato-duodenectomy(PPPD) for pancreatic adenocarcinoma, after 12 months presented with symptoms of gastric outlet obstruction (GOO). Computed tomography(CT) scan showed tumor recurrence at the efferent jejunal $\operatorname{loop}(\mathrm{EJ} \mathrm{L})$, determining stomach dilation, peritoneal carcinomatosis and ascites ( $\triangleright$ Fig. $\mathbf{1}$ ). The case was discussed at our multidisciplinary meeting: due to advanced stage of disease and patient's comorbidities, a palliative approach by endoscopic ultrasound guided gastroenterostomy(EUS-GE) was planned.

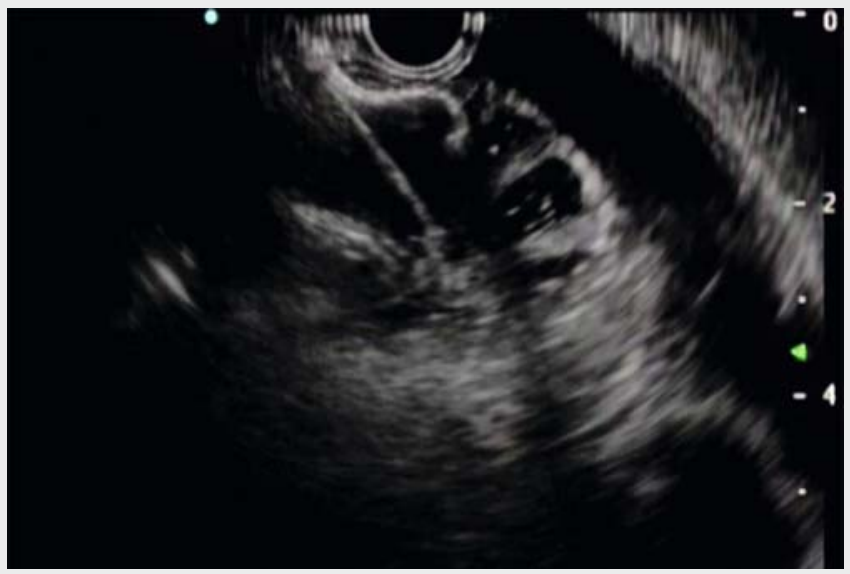

$\checkmark$ Video 1 Endoscopic ultrasound-guided gastroenterostomy (EUS-GE) to manage malignant gastric outlet obstruction in a pylorus-preserving pancreaticoduodenectomy (PPPD) reconstruction for tumor recurrence at the efferent limb.

An upper Gl endoscope was advanced till the EJL strictures and a $7.5 \mathrm{Fr}$ oro-jejunal catheter was placed across the stricture over a wire, for injecting normal saline mixed with contrast and methylene blue in order to optimize small bowel distension. Under EUS and fluoroscopy guidance a small bowel loop close to the stomach within ascitic fluid was identified and punctured with a 19-gauge needle ( $\mathbf{F i g . 2}$, Video 1). Aspiration of blue fluid confirmed the correct location and a 0.035-inch guidewire was advanced through the needle into the efferent limb. A $15 \times 10$ mm electrocautery enhanced lumen apposing metal stent (EC-LAMS) (Hot-Axios, Boston Scientific Corp, Marlborough, Mass, USA) was placed on the guidewire and the blue fluid coming through the stent confirmed the correct enterogastric deployment( Fig. 3-4).

Post-procedural course was uneventful. A progressive oral re-intake was administered and a full solid diet was possible three days after the procedure. Patient died 2 months later, due to disease's progression, without evidence of $\mathrm{GOO}$ symptoms recurrence. 


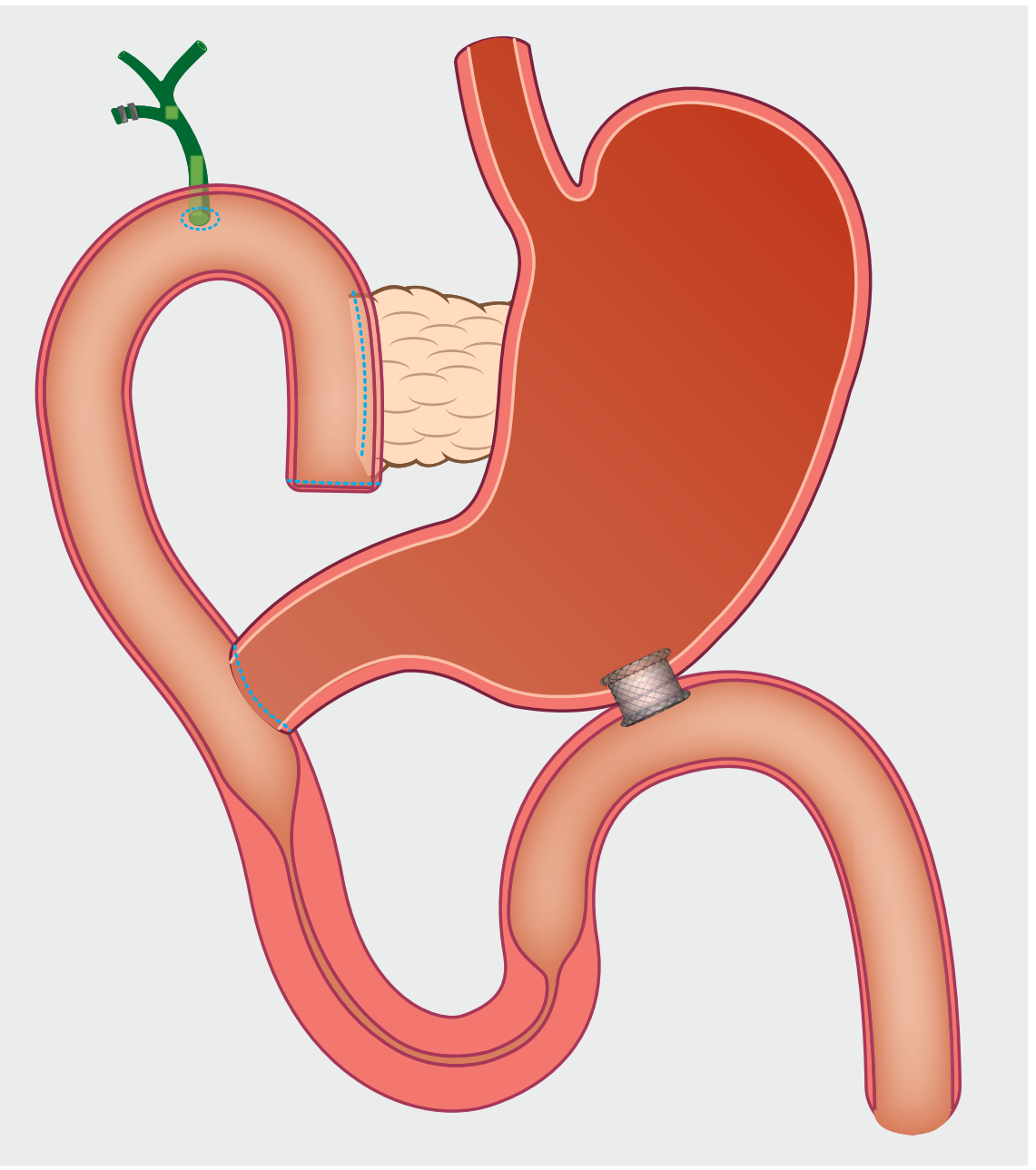

- Fig.4 Graphic representation of the Endoscopic ultrasound-guided gastroenterostomy (EUS-GE) for malignant gastric outlet obstruction in a pylorus-preserving pancreaticoduodenectomy (PPPD) reconstruction for tumor recurrence at the efferent limb.

After curative surgery for pancreatic cancer up to $60 \%$ of patients develop local and systemic recurrence within the first 12 months [1]. In some cases, recurrence at gastro-jejunal anastomosis or peritoneal carcinomatosis determines GOO. Historically, EJL obstruction has been treated with open surgical gastrojejunostomy or enteral stents. EUS-GE using LAMS has been demonstrated as an effective and safe procedure in the management of GOO for duodenal obstruction with high technical and clinical success rate [2-4]. Recently a case of EUS-guided drainage with LAMS of an obstructed afferent loop has been published with promising results [5]. Our report firstly demonstrated that palliation of GOO by EUS$\mathrm{GE}$ can be proposed as an effective alternative approach even in patients with previous PPPD with EJL obstruction.

\section{Competing interests}

A. Anderloni: consultant for Boston Scientific, Olympus, and Medtronic. A. Repici: consultant for Boston Scientific and Fujifilm. All other authors disclosed no financial relationships.

The authors

Alessandro Fugazza', Matteo Colombo', Annalisa Cappello ${ }^{1}$, Gennaro Nappo ${ }^{2}$, Alessandro Zerbi ${ }^{2,3}$, Alessandro Repici ${ }^{1,3}$, Andrea Anderloni ${ }^{1}$

1 Digestive Endoscopy Unit, Division of Gastroenterology, Humanitas Clinical and Research Center - IRCCS, Via Manzoni 56, 20089 Rozzano (Milano), Italy

2 Pancreatic Surgery Unit, Humanitas Clinical and Research Center - IRCCS, Via Manzoni 56, 20089 Rozzano (Milano), Italy
3 Humanitas University, Department of Biomedical Sciences, Pieve Emanuele (MI) Italy

\section{Corresponding author}

\section{Alessandro Fugazza}

Digestive Endoscopy Unit, Division of Gastroenterology, Humanitas Clinical and Research Center - IRCCS, Via Manzoni 56 , 20089 Rozzano (Milano), Italy alessandro.fugazza@humanitas.it

\section{References}

[1] La Torre M, Nigri G, Lo Conte A et al. Is a preoperative assessment of the early recurrence of pancreatic cancer possible after complete surgical resection? Gut Liver 2014; 8: 102-108. doi:10.5009/gnl.2014.8.1.102

[2] Troncone E, Fugazza A, Cappello A et al. Malignant gastric outlet obstruction: Which is the best therapeutic option? World J Gastroenterol 2020; 26: 1847-1860. doi:10.3748/wjg.v26.i16.1847

[3] Mussetto A, Fugazza A, Fuccio L et al. Current uses and outcomes of lumen-apposing metal stents. Ann Gastroenterol 2018; 31: 535-540. doi:10.20524/aog.2018.0287

[4] Iqbal U, Khara HS, Hu Y et al. EUS-guided gastroenterostomy for the management of gastric outlet obstruction: A systematic review and meta-analysis. Endosc Ultrasound 2020; 9: 16-23. doi:10.4103/eus. eus_70_19

[5] Ligresti D, Amata M, Messina M et al. Singlestep EUS-guided jejunojejunostomy with a lumen-apposing metal stent as treatment for malignant afferent limb syndrome. VideoGIE 2020; 5: 154-156. doi:10.1016/j. vgie.2019.12.011

\section{Bibliography}

DOI http://dx.doi.org/10.1055/a-1221-5183

Endoscopy International Open 2020; 08: E1435E1436

Georg Thieme Verlag KG

Rüdigerstraße 14,

70469 Stuttgart, Germany

eISSN 2196-9736

(C) 2020. The Author(s).

This is an open access article published by Thieme under the terms of the Creative Commons Attribution-NonDerivative-NonCommercial License, permitting copying and reproduction so long as the original work is given appropriate credit. Contents may not be used for commecial purposes, or adapted, remixed, transformed or built upon. (https://creativecommons.org/licenses/by-nc-nd/4.0/)

\section{(ㄱ)(1) $\circledast 2$}

